\title{
Modifikasi Jembatan Sembayat Baru II Menggunakan Sistem Jembatan Busur Rangka Baja
}

\author{
Rio Prasmoro, Hidayat Soegihardjo Masiran, dan Endah Wahyuni \\ Jurusan Teknik Sipil, Fakultas Teknik Sipil dan Perencanaan, Institut Teknologi Sepuluh Nopember (ITS) \\ Jl. Arif Rahman Hakim, Surabaya 60111 \\ e-mail: hidayat@ce.its.ac.id, endah@ce.its.ac.id
}

\begin{abstract}
Abstrak-Perencanaan struktur jembatan perlu mempertimbangkan desain yang tepat agar material yang digunakan menjadi efektif. Jembatan Sembayat Baru II di Kabupaten Gresik yang didesain menggunakan jembatan busur beton dengan bentang $93 \mathrm{~m}$ dimana terdapat pilar pada badan sungai, menjadi tidak efektif karena dapat mengurangi effective linear waterway sungai tersebut. Pertimbangan jembatan bentang panjang yang berupa busur merupakan keputusan yang tepat, hanya saja bentang yang didesain masih kurang maksimal. Dalam perencanaan ini, jembatan Sembayat Baru II didesain dengan tetap menggunakan jembatan busur namun material beton dirubah menjadi material baja, dimana dengan penggunaan material baja, bentang jembatan dapat lebih maksimal. Sehingga dari desain awal yang terdapat 5 bentang jembatan prategang dan 1 bentang jembatan busur, dirubah menjadi 4 bentang jembatan prategang dan 1 jembatan busur tipe a half through arch dengan bentang $144 \mathrm{~m}$.

Dasar perencanaan jembatan mengacu pada peraturan BMS 1992 dan SNI 1729-2015. Analisis perhitungan struktur utama dan sekunder menggunakan bantuan software MIDAS Civil 2011. Dari hasil perencanaan, didapat profil struktur busur utama yaitu menggunakan profil Box $800 \times 500 \times 38 \times 38$ dan batang tarik menggunakan profil Box 800x600x45x45. Perhitungan accidental load yang berupa 1 batang penggantung putus menghasilkan kesimpulan bahwa jembatan masih mampu menahan beban layan selama masa perbaikan. Metode pelaksanaan yang ditinjau menggunakan sistem Full Cantilever.
\end{abstract}

Kata Kunci - accidental load, half through arch, jembatan busur, metode pelaksanaan

\section{PENDAHULUAN}

$\mathrm{K}$ ONDISI saat ini di jembatan Sembayat, Kabupaten Gresik, Provinsi Jawa Timur sedang dilakukan pembangunan jembatan sembayat II yang merupakan infrastruktur tambahan guna mengakomodasi pertum-buhan kendaraan yang semakin hari semakin padat di jalur alternatif pantura tersebut. Pembangunan jem-batan sembayat II menggunakan konstruksi gabungan antara jembatan gelagar beton sepanjang $354 \mathrm{~m}$ dan jembatan busur beton dibentang terpanjangnya yaitu $93 \mathrm{~m}$.

Pertimbangan menggunakan jembatan busur memang tepat, namun bentang maksimum yang dapat dijangkau oleh jembatan pelengkung dengan material beton tidaklah sejauh jembatan pelengkung dengan material baja, baik rangka ataupun plate girder. Jembatan pelengkung dari beton memiliki bentang maksimum $420 \mathrm{~m}$, sedangkan jembatan pelengkung dari baja memiliki bentang maksimum $550 \mathrm{~m}$.
Untuk itu, penelitian ini dibuat untuk me-modifikasi struktur jembatan sembayat Baru II yang mulanya menggunakan jembatan busur dari beton, dirubah menjadi jembatan busur dengan rangka baja.

A. Rumusan Masalah

Permasalahan Utama

Bagaimana merencanakan jembatan busur yang ekonomis dan efisien?

B. Tujuan Penelitian

Tujuan Utama

Dapat merencanakan jembatan busur yang ekon-omis dan efisien

C. Batasan Masalah

1. Perencanaan jembatan ini hanya meninjau str-uktur saja (tidak menghitung analisis biaya dan manajemen konstruksi).

2. Tidak merencanakan perkerasan jalan di jembatan

3. Tidak merencanakan substruktur jem-batan.

4. Perumusan yang digunakan sesuai dengan literatur yang ada.

5. Hanya meninjau 1 cara metode pelaksanaan.

6. Accidental load yang ditinjau hanya 1 kabel penggantung yang terputus.

D. Manfaat Penelitian

1. Sebagai referensi dalam mendesain jembatan dengan menggunakan sistem jembatan busur.

2. Sebagai bahan pertimbangan dalam men-desain jembatan bagi instansi terkait.

\section{STUDI PUSTAKA}

A. Umum

Jembatan busur banyak dipergunakan sebagai jembatan bentang panjang karena bentuk busur pada struktur pemikul utama mampu mengurangi nilai momen lapangan yang terjadi akibat beban luar. Sehingga dengan bentang yang sama, dimensi jembatan busur dapat lebih kecil daripada jembatan girder [1].

- $\quad$ Tinggi dari batang lengkung/tinggi busur (focus), dapat direncanakan sebesar:

$$
\frac{1}{6} \leq \frac{\mathrm{f}}{\mathrm{L}} \leq \frac{1}{5}
$$


- Perbandingan lebar jembatan dan panjang bentang, direncanakan:

$$
\frac{\mathrm{b}}{\mathrm{L}} \geq \frac{1}{20}
$$

- Perbandingan antara tinggi tampang busur dan panjang bentang busur, direncanakan:

$$
\frac{1}{80} \leq \frac{\mathrm{t}}{\mathrm{L}} \leq \frac{1}{70}
$$

\section{METODOLOGI PENELITIAN}

A. Tahap Pengumpulan Data

Data Sungai:

- Lebar sungai: $133 \mathrm{~m}$

- Elevasi dasar sungai: $-15 \mathrm{~m}$

- $\quad$ Elevasi M.A.T: +1.794

- Kondisi eksisting:

- $\quad$ Bentang jembatan: $354 \mathrm{~m}$

- 93 meter jembatan busur beton

- 261 meter jembatan beton pratekan

- Lebar jembatan $12 \mathrm{~m}$

B. Preliminary Design

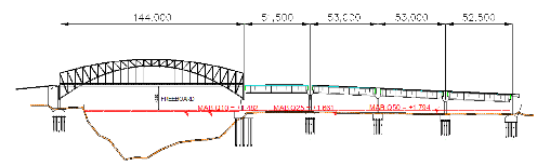

Gambar 1 Modifikasi Jembatan Sembayat Baru II

Bentang jembatan busur dirubah menjadi $144 \mathrm{~m}$, menggunakan material baja.

C. Pembebanan Jembatan

Pembebanan jembatan disesuaikan dengan SNI 1725-2016 tentang Pembebanan Untuk Jembatan.

- $\quad$ Beban mati $=350,4 \mathrm{kN}$

- $\quad$ Beban hidup $=192,5 \mathrm{kN} / \mathrm{m}$

- Beban angin berdasarkan ketinggian titik buhul.

- $\quad$ Beban angin kendaraan $=2,628$ kN.m

- $\quad$ Beban temperatur $=\quad \min =15^{\circ} \mathrm{C}$

$\max =40^{\circ} \mathrm{C}$

- $\quad$ Beban gempa (Respon spektrum)

$$
\begin{array}{ll}
\mathrm{T}_{0} & =0,161 \text { detik } \\
\mathrm{T}_{\mathrm{S}} & =0,804 \text { detik }
\end{array}
$$

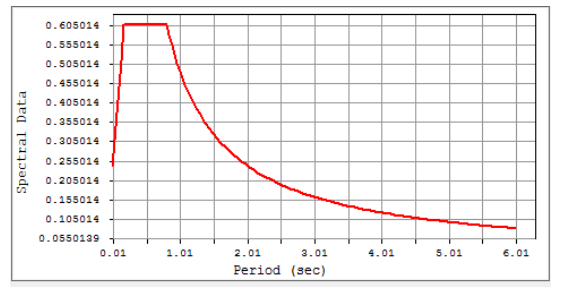

Gambar 2. Respon Spektrum Kota Gresik

- $\quad$ Base Shear total jembatan

Vstatik $=\frac{C s m}{R} W t$

Base Shear arah X
$\operatorname{Vstatik}(\mathrm{X})=\frac{C s m}{R} W t=2.744,61 \mathrm{kN}$

0,85 Vstatik $=0,85 \times 2.744,61 \mathrm{kN}=2.332,92 \mathrm{kN}$

Base Shear arah Y

Vstatik $\quad=\frac{C s m}{R} W t=1.829,74 \mathrm{kN}$

0,85 Vstatik $=0,85 \times 1.829,74 \mathrm{kN}=1.555,28 \mathrm{kN}$

$\operatorname{Vdinamik}(\mathrm{X})=7.773,96 \mathrm{kN}$

$\operatorname{Vdinamik}(\mathrm{Y})=7.697,83 \mathrm{kN}$

Nilai $\mathrm{R}$ pada gempa arah $\mathrm{x}$ lebih besar karena tidak diperbolehkan adanya leleh pada elemen jembatan, namun pada arah y diperbolehkan yaitu pada bagian portal akhir.

Kombinasi pembebanan [2], disesuaikan dengan beban yang bekerja pada jembatan.

Tabel 1

Kombinasi Pembebanan

\begin{tabular}{ccccccc}
\hline \hline Comb. & DL & LL & EW $_{\mathrm{S}}$ & $\mathrm{EW}_{\mathrm{L}}$ & $\mathrm{ET}$ & $\mathrm{EQ}$ \\
\hline 1 & 1 & 2 & - & - & 0,5 & - \\
2 & 1 & - & 1,4 & - & 0,5 & - \\
3 & 1 & - & 0,4 & 1 & 0,5 & - \\
4 & 1 & 0,5 & - & - & - & 1 \\
5 & 1 & 1 & 0,3 & 1 & 1,2 & - \\
\hline
\end{tabular}

D. Pemodelan Struktur

Pemodelan untuk jembatan ini menggunakan software Midas CIVIL 2011 secara 3 dimensi.

E. Kontrol Stabilitas

Kontrol stabilitas berdasarkan pada [3] tentang Spesifikasi Untuk Bangunan Gedung Baja Struktural.

F. Staging Analysis

Metode pelaksanaan menggunakan sistem Full Cantilever. (Xiang, Zhongfu. et al. 2013)

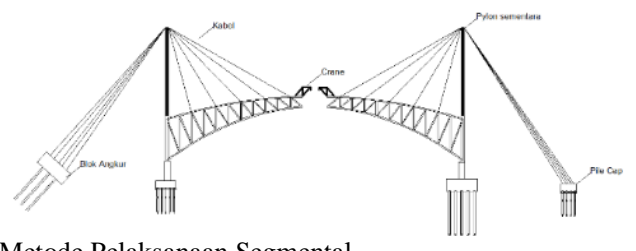

Gambar 3 Metode Pelaksanaan Segmental

Pelaksanaan jembatan dilaksanakan segmental dari portal akhir sampai lantai kendaraan terpasang pada jembatan.

\section{HASIL DAN PEMBAHASAN}

A. Perencanaan Pelat Lantai

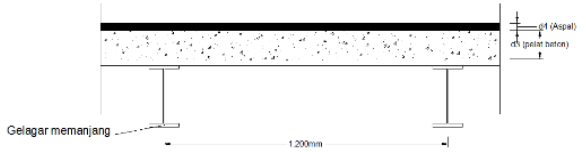

Gambar 4 Pelat Lantai Kendaraan 
- Penulangan Pelat Lantai

Tebal pelat $=200 \mathrm{~mm}$

f'c beton $=35 \mathrm{MPa}$

fy tulangan $=360 \mathrm{MPa}$

Decking beton $=40 \mathrm{~mm}$

$\emptyset$ tulangan $=\mathrm{D} 19 \mathrm{~mm}$ (melintang)

$\emptyset$ tulangan $=\varnothing 12 \mathrm{~mm}$ (memanjang)

Tulangan melintang D19-250

$\rightarrow$ As pakai $=1.031 \mathrm{~mm} 2$

Tulangan memanjang $\emptyset 12-250$

$\rightarrow$ As pakai $=452 \mathrm{~mm}^{2}$

\section{Gambar 5 Penulangan Pelat Lantai}

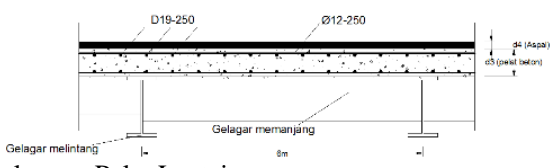

B. Gelagar Memanjang

Data gelagar:

WF $500 \times 200 \times 10 \times 16$

$\mathrm{Mu}<\varnothing \mathrm{Mn}$

488,38 kN.m $<610,65$ kN.m $\rightarrow$ OK

Lendutan

$\Delta \mathrm{ijin}=\lambda / 800=600 / 800=0,75 \mathrm{~cm}$

Lendutan akibat truk $=0,65 \mathrm{~cm}$

$\Delta$ terjadi $<\Delta$ ijin $\rightarrow$ OK

C. Gelagar Melintang

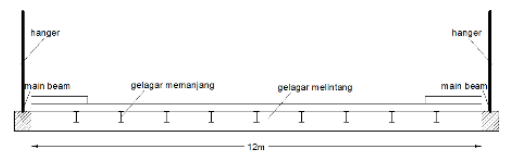

Gambar 7 Gelagar Memanjang

Data gelagar:

WF 800 × $300 \times 14$ × 22

- Penampang komposit

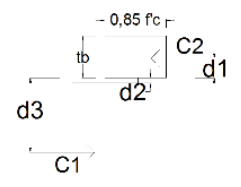

Gambar 8 Diagram Komposit

$\mathrm{Mu}<\varnothing \mathrm{Mn}$

$3.477,42 \mathrm{kN} . \mathrm{m}<3976,07 \mathrm{kN} . \mathrm{m} \rightarrow$ OK

- Kontrol lendutan

$\Delta \mathrm{ijin}=\lambda / 800=1200 / 800=1,5 \mathrm{~cm}$

$\Delta$ terjadi $=1,03 \mathrm{~cm}$

$\Delta$ terjadi $<\Delta$ ijin $\rightarrow$ OK
D. Rangka Utama

Data profil:

Box 800x500x38x38

- Kontrol batang tekan

$\varnothing \mathrm{Nn}=0,9 \times$ Fcr $\times \mathrm{Ag}=33.304,44 \mathrm{kN}$

$\mathrm{Nu}=14.236,4 \mathrm{kN}$

$\mathrm{Nu}<\varnothing \mathrm{Nn} \rightarrow \mathrm{OK}$

- Kontrol flexural buckling

$\frac{\mathrm{h}}{\mathrm{tw}}<1,12 \sqrt{\frac{\mathrm{E}}{\mathrm{fy}}}=19,05<25,34$

Penampang kompak $\rightarrow \mathrm{Mn}=\mathrm{Mp}$

$\varnothing \mathrm{Mn}=0,9 \mathrm{x} \mathrm{Zx} \times$ fy $=9.017,37 \mathrm{kN} \cdot \mathrm{m}$

$\mathrm{Mu}=1.695,47 \mathrm{kN} \cdot \mathrm{m}$

$\mathrm{Mu}<\varnothing \mathrm{Mn} \rightarrow$ OK

- Kontrol torsional buckling

$\varnothing \mathrm{Tn}=0,9 \times$ Fcr $\times \mathrm{C}=5.876,7 \mathrm{kN} . \mathrm{m}$

$\mathrm{Tu}=237,27 \mathrm{kN} . \mathrm{m}$

$\mathrm{Tu}<\varnothing \mathrm{Tn} \rightarrow$ OK

- Kontrol geser

$\varnothing \mathrm{Vn}=0,9 \times \mathrm{Fcr} \times \mathrm{Ag} / 2=12.182,31 \mathrm{kN} \cdot \mathrm{m}$

$\mathrm{Vu}=340,09 \mathrm{kN} . \mathrm{m}$

$\mathrm{Vu}<\varnothing \mathrm{Vn} \rightarrow \mathrm{OK}$

- Kontrol interaksi gaya torsi, geser, lentur, dan aksial

Cek: $\frac{\mathrm{Tu}}{\varphi \mathrm{Tn}}=0,04<0,2$

Maka gaya torsi diabaikan

Cek: $\frac{\mathrm{Nu}}{\varphi \mathrm{Nn}}=0,42>0,2$

$\frac{\mathrm{Nu}}{\varphi \mathrm{Nn}}+\frac{8}{9}\left(\frac{\mathrm{Mux}}{\varphi_{\mathrm{b}} \mathrm{x} \mathrm{Mnx}}+\frac{\text { Muy }}{\varphi_{\mathrm{b}} \mathrm{x} \text { Mny }}\right)<1,0$

$0,64<1 \rightarrow$ OK

Dengan kontrol yang sama, didapat rasio elemen pada batang jembatan yang lain yaitu:

Tabel 2.

Rasio Elemen Jembatan

\begin{tabular}{ll}
\hline \hline Elemen & Rasio \\
\hline Busur atas & 0,64 \\
Busur bawah & 0,81 \\
Diagonal* & 0,84 \\
Vertikal* & 0,86 \\
Main Girder & 0,88 \\
\hline \hline
\end{tabular}

Untuk elemen diagonal dan vertikal, kontrol batang hanya berupa kontrol tekan dan tarik saja.

E. Perencanaan Batang Penggantung

Gambar 9 Batang Penggantung

Digunakan batang penggantung fabrikasi dari Macalloy jenis Macalloy 520 (M72), Carbon steel.

Data hanger:

$\emptyset$ batang $=72 \mathrm{~mm}$

$\mathrm{W}$ kabel $=32 \mathrm{~kg} / \mathrm{m}$ 
Minimum Break Load $=2.635 \mathrm{kN}$

Kontrol kekuatan hanger

$\mathrm{Pu}=1.252,95 \mathrm{kN}$

$\mathrm{Pu}<$ Minimum Break Load $\rightarrow$ OK

- Sambungan hanger

Data pin:

$\emptyset$ pin $=78,5 \mathrm{~mm}$

F. Sambungan busur atas

Data sambungan:

$\emptyset$ baut $=32 \mathrm{~mm}($ ASTM A325)

Pelat $=19 \mathrm{~mm}$

- $\quad$ Beban yang bekerja arah $\mathrm{x}(\mathrm{Rx})$

$\mathrm{P}=14.236,4 \mathrm{kN}$

$\frac{\mathrm{My}}{\mathrm{H}}=\frac{1.695,47 \mathrm{kN} \cdot \mathrm{m}}{0,8 \mathrm{~m}}=2.119,33 \mathrm{kN}$

$\frac{\mathrm{Mz}}{\mathrm{B}}=\frac{444,06 \mathrm{kN} \cdot \mathrm{m}}{0,5 \mathrm{~m}}=888,12 \mathrm{kN}$

Total $\mathrm{Rx}=17.243,85 \mathrm{kN}$

$\mathrm{Rx} 1$ pada sayap=

$\left(\frac{\mathrm{B}}{\mathrm{B}+\mathrm{H}}\right) \times 1 / 2 \mathrm{Rx}=3.316,12 \mathrm{kN}$

$\mathrm{R} \times 2$ pada badan $=$

$\left(\frac{\mathrm{H}}{\mathrm{B}+\mathrm{H}}\right) \times 1 / 2 \mathrm{Rx}=5.305,8 \mathrm{kN}$

- Beban yang bekerja arah y (Ry)

$\mathrm{Vy}=82,58 \mathrm{kN}$

$\frac{\left(\frac{\mathrm{B}}{\mathrm{B}+\mathrm{H}}\right) \times \mathrm{T}}{\mathrm{H}}=114,07 \mathrm{kN}$

Total Ry $=196,65 \mathrm{kN}$

- Beban yang bekerja arah z (Rz)

$\mathrm{Vz}=340,09 \mathrm{kN}$

$\frac{\left(\frac{\mathrm{H}}{\mathrm{B}+\mathrm{H}}\right) \times \mathrm{T}}{\mathrm{B}}=292,02 \mathrm{kN}$

Total $\mathrm{Rz}=632,11 \mathrm{kN}$

Resultan gaya pada sayap:

$\mathrm{R}_{1}=\sqrt{\mathrm{Rx}^{2}+\mathrm{Ry}^{2}}=3.321,94 \mathrm{kN}$

Jumlah baut (n) pada sayap $=\frac{\mathrm{R}_{1}}{\mathrm{Vd}}$

$\mathrm{n}=\frac{3.321,94 \mathrm{kN}}{279,11 \mathrm{kN}}=11,9 \approx 12$ baut

Resultan gaya pada badan

$\mathrm{R}_{2}=\sqrt{\mathrm{Rx}^{2}+\mathrm{Rz}^{2}}=5.343,32 \mathrm{kN}$

Jumlah baut (n) pada badan $=\frac{\mathrm{R}_{2}}{\mathrm{Vd}}$

$\mathrm{n}=\frac{5.343,32 \mathrm{kN}}{279,11 \mathrm{kN}}=19,14 \approx 20$ baut
G. Kontrol Accidental Load

Kontrol accidental load merupakan kontrol jembatan dimana terdapat kondisi 1 hanger putus, kontrol ini diperlukan agar jembatan masih mampu menahan beban layan selama proses maintenance dilakukan.

Dari hasil analisis, didapat rasio kontrol interaksi gaya untuk masing-masing elemen yaitu sebagai berikut:

Tabel 3

Rasio Elemen Akibat Accidental Load

\begin{tabular}{ccc}
\hline \hline Elemen & Rasio & Kontrol < 1 \\
\hline Busur atas & 0,96 & OK \\
Busur bawah & 0,9 & OK \\
Diagonal & 0,8 & OK \\
Vertikal & 0,98 & OK \\
Main girder & 0,94 & OK \\
\hline \hline
\end{tabular}

Dari tabel diatas, didapat rasio mendekati 1, yang artinya elemen busur hampir mencapai tegangan maksimum. Untuk itu diperlukan perbaikan segera.

H. Design Perletakan

Perletakan yang digunakan dalam perencanaan ini yaitu tipe pot bearing fabrikasi Technoslide, dengan asumsi sebagai berikut:
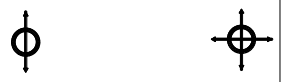

Gambar 10 Perletakan Jembatan

Dimana terdapat 3 jenis perletakan tipe pot bearing. $=$ Jenis perletakan tipe fixed, dimana tidak ada pergerakan arah horisontal

= Jenis perletakan tipe unidirection, dimana dimungkinkan pergerakan arah horisontal pada 1 arah saja

$=$ Jenis perletakan tipe multidirection, dimana dimungkinkan pergerakan arah horisontal pada semua arah.

- Perletakan fixed

Gaya yang bekerja pada perletakan:

$\mathrm{Fx}=886,81 \mathrm{kN}$

$\mathrm{Fy}=69,23 \mathrm{kN}$

$\mathrm{Fz}=9.849,37 \mathrm{kN}$

Resultan FX dan Fy $=889,5 \mathrm{kN}$

Digunakan perletakan tipe BTF 1000/20

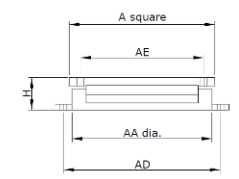

Gambar 11 Perletakan Tipe Fixed

- Perletakan unidirection $\mathrm{x}$

Gaya yang bekerja:

$\mathrm{Fy}=30,49 \mathrm{kN}$

$\mathrm{Fz}=9.689,08 \mathrm{kN}$ 
Digunakan perletakan tipe BTU 1000/20/*

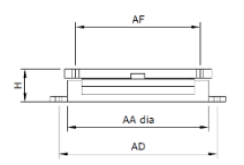

Gambar 12 Perletakan Tipe Unidirection

- Perletakan unidirection y

Gaya yang bekerja:

$\mathrm{Fx}=870,65 \mathrm{kN}$

$\mathrm{Fz}=9.859,9 \mathrm{kN}$

Digunakan perletakan tipe BTU 1000/20/*

Gambar 13 Perletakan Tipe Unidirection

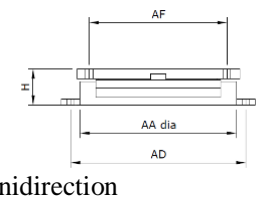

- Perletakan multidirection

Gaya yang bekerja:

$\mathrm{Fz}=9.716,25 \mathrm{kN}$

Digunakan perletakan tipe BTA 1000/20/*/*

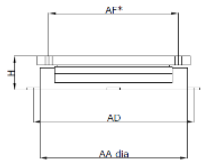

Gambar 14 Perletakan Tipe Multidirection

\section{STAGING ANALYSIS}

- Metode Pelaksanaan

Metode pelaksanaan yang digunakan yaitu sistem Full Cantilever, dimana digunakan pilar bantuan untuk tempat menggantung kabel selama menopang jembatan saat proses pelaksanaan.

- $\quad$ Stage 1

Gambar 15 Stage 1

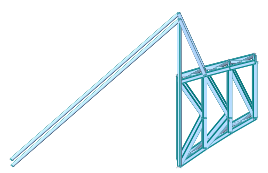

Segmen pertama dipasang bersamaan 3 segmen dimana kabel penggantung (1) diberi tension sebesar 350 $\mathrm{kN}$ dan kabel backstay diberi tension sebesar $400 \mathrm{kN}$.

- $\quad$ Stage 2

Gambar 16 Stage 2

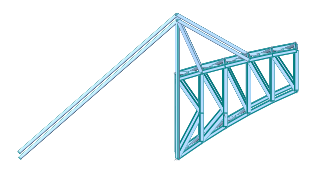

Segmen berikutnya dipasang 2 segmen dengan tambahan kabel penggantung (2) yang diberi tension sebesar $500 \mathrm{kN}$.
- $\quad$ Stage 3

Gambar 17 Stage 3

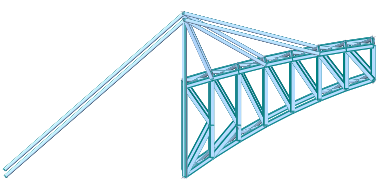

Segmen berikutnya dipasang kembali 2 segmen dengan kabel penggantung (3) yang diberi tesion sebesar $500 \mathrm{kN}$, dan kabel backstay diberi tension hingga $550 \mathrm{kN}$.

- $\quad$ Stage 4

Gambar 18 Stage 4

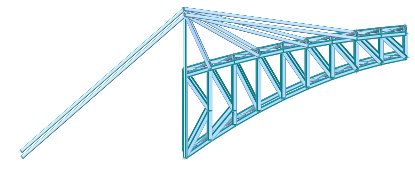

Segmen berikutnya dipasang 2 segmen dengan kabel penggantung (4) yang diberi tension $500 \mathrm{kN}$.

- $\quad$ Stage 5

Gambar 19 Stage 5

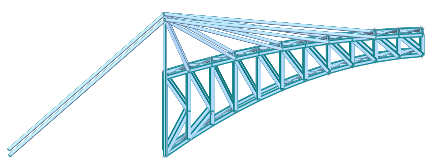

Segmen puncak busur dipasang dan diberi kabel penggantung (5) yang diberi tension $500 \mathrm{kN}$, dan kabel backstay diberi tension tambahan hingga $900 \mathrm{kN}$.

- $\quad$ Stage 6

Gambar 20 Stage 6

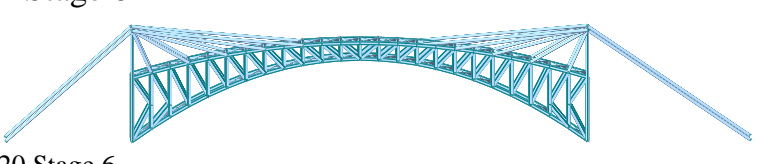

Segmen puncak (Closure) dipasang, pada tahap ini segmen kritis diperhitungkan dimana busur sudah terpasang namun masih belum mampu menahan gaya horisontal yang terjadi akibat berat sendiri.

- $\quad$ Stage 7

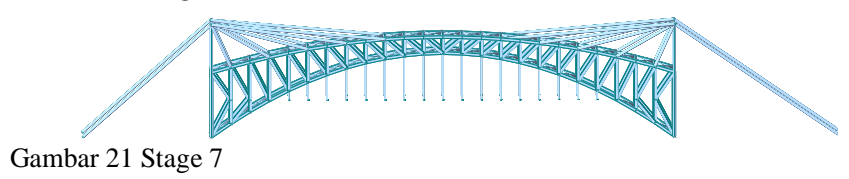
buhul.

Pemasangan batang penggantung pada setiap titik

- $\quad$ Stage 8

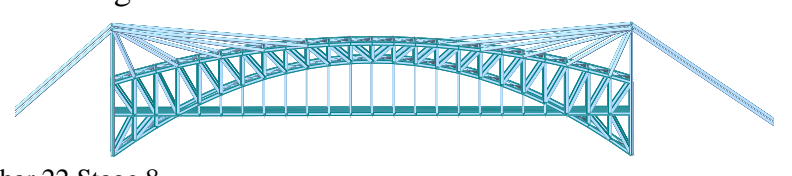

Gambar 22 Stage 8

Pemasangan tie beam, gelagar melintang, gelagar memanjang dan pekerjaan lantai kendaraan serta aksesoris jembatan. 
- $\quad$ Stage 9

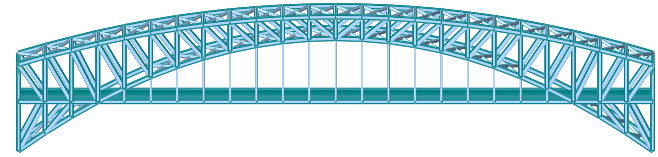

Gambar 23 Stage 9

Penghilangan gaya kabel dan pembongkaran tower pembantu.

- Kontrol segmen kritis

Segmen kritis yang ditinjau yaitu pada saat stage 6, dimana struktur busur sudah tersambung. Perhitungan berdasarkan kombinasi 2 dimana beban angin pada struktur bekerja.

Dari hasil perhitungan kontrol interaksi gaya torsi, geser, lentur dan aksial, didapat:

$\frac{\mathrm{Nu}}{\varphi \mathrm{Nn}}+\frac{8}{9}\left(\frac{\mathrm{Mux}}{\varphi_{\mathrm{b}} \mathrm{x} \mathrm{Mnx}}+\frac{\text { Muy }}{\varphi_{\mathrm{b}} \mathrm{x} \text { Mny }}\right)<1,0$

$0,96<1 \rightarrow$ OK

\section{KESIMPULAN}

A. Kesimpulan

1. Dimensi melintang jembatan yaitu $9 \mathrm{~m}$ lantai kendaraan dan $2 \times 1,5 \mathrm{~m}$ trotoar.

2. Lantai kendaraan memiliki ketebalan $20 \mathrm{~cm}$ dengan mutu f'c $30 \mathrm{MPa}$ dan perkerasan aspal $5 \mathrm{~cm}$. Tulangan arah melintang pada pelat beton yaitu D19-250 dan arah memanjang $\varnothing 12-250$.

3. Profil gelagar memanjang: WF 500x200x10x16, gelagar melintang: WF $800 \times 300 \times 14 \times 22$, main girder: Box $800 \times 600 \times 45 \times 45$, busur atas dan bawah: Box $800 \times 500 \times 38 \times 38$, diagonal dan vertikal: WF 500x500x16×25, ikatan angin atas: Ø16", ikatan angin bawah: Ø24" dan Box 500x300x16x25, ikatan silang: Ø14", balok portal akhir: Ø10", dan kolom portal akhir: Box 800x500x38x38.

4. Hanger menggunakan fabrikasi dari Macalloy dengan tipe Macalloy 520 (M72) dengan diameter $72 \mathrm{~mm}$.

5. Perletakan menggunakan pot bearing dengan tipe:

- $\quad$ Tipe fixed = BTF $1000 / 20$

- Tipe unilateral $\mathrm{x}=\mathrm{BTU} 1000 / 20 / *$

- Tipe unilateral $\mathrm{y}=\mathrm{BTU} 1600 / 20 / *$

- $\quad$ Tipe multilateral $=$ BTA $1000 / 20 / * / *$

6. Profil yang didapat, masih mampu menahan beban layan saat terjadi kondisi kegagalan hanger.

\section{DAFTAR PUSTAKA}

[1] Soegihardjo, Hidayat. Diktat Kuliah Bentang Panjang. Fakultas Teknik Sipil dan Perencanaan. Institut Teknologi Sepuluh Nopember, Surabaya.

[2] SNI 1725-2016. Pembebanan Untuk Jembatan.

[3] SNI 1729-2015. Spesifikasi Baja Untuk Bangunan Gedung Baja Struktural.

[4] Xiang, Zhongfu., Xu, Wei., Wang, Cunshu., and Dong, Ying., 2010. "The Construction Technology of Chongqing Chiaotianmen Bridge". International Conference on Arch Bridge. 